\title{
Continuous powder mixing of segregating mixtures under steady and unsteady state regimes: Homogeneity assessment by real-time on-line image analysis
}

\author{
C. Ammarcha ${ }^{\text {a }}$, C. Gatumel ${ }^{\text {a }}$, J.L. Dirion ${ }^{\text {a }}$, M. Cabassud ${ }^{\text {b }}$, H. Berthiaux ${ }^{\mathrm{a}, *}$ \\ a Université de Toulouse, Mines Albi, UMR CNRS 5302, Centre RAPSODEE, Campus Jarlard, F-81013 Albi Cedex 09, France \\ b Université de Toulouse, Laboratoire de Génie Chimique, UMR 5503 CNRS-INPT-UPS, Campus INPT-ENSIACET, 4 allée Emile Monso, BP 84234, F-31432 Toulouse Cedex 04, France
}

\begin{abstract}
A B S T R A C T
Continuous powder processes, such as continuous powder mixing, are more than ever envisioned as a viable alternative to batch equipment, in various industries such as pharmaceuticals, specialty chemicals (zeolites, $\mathrm{SiC}$ ), bio-renewables or food. In the present work we have implemented an on-line image analysis set-up that is able to capture all the images of the particles at the outlet of a continuous pilot-scale mixer. This allows the determination of the homogeneity of mixtures of two different compositions, as well as the analysis of their evolution during steady-state and transitory regimes. The importance of a proper definition of the scale of scrutiny of the mixture is emphasized by providing homogeneity results obtained at four different scales. Evidence of segregation by percolation giving rise to the enrichment of the mixer's bed with fine particles is given and commented. The impact of the stirrer's rotational speed on the quality of the mixtures, as provided by the coefficient of variation CV, is reported. Up to $20 \mathrm{~Hz}$, CV's are extremely high, while above $30 \mathrm{~Hz}$, the influence of the impeller speed is much weaker. Finally, the influence of impeller speed's step perturbations is measured and commented. Due to the size - segregation phenomenon inside the mixer, negative steps are deeply detrimental to the mixing process. On the contrary, positive steps can be absorbed by the equipment without degradation of the quality of the mixtures.
\end{abstract}

\section{Introduction}

Bakery mixes, icing sugar, curry powder, aspirin pills, cement bags, are all common examples of powder mixtures we all deal with in our everyday life. Acrylic cements for surgery use, uranium-plutonium oxide mixtures for nuclear fuel, graphite - thermoplastic resin mix for bipolar plates in fuel cell technology, cobalt-tungsten-diamond mixtures for the processing of highly resistant tools, are certainly lesserknown examples of powder mixtures, while they eventually lead to higher added value products. For all these applications, and many more, a specific mixing technology has to be defined and optimized. And a specific route has to be chosen: batch or continuous?

Continuous processes are usually disregarded when considering small capacity manufacturing, extremely diversified production, or reactive systems of slow kinetics. Conversely, they are obvious for high-profile, low-cost and high-tonnage products. In between, lays the wide majority of goods for which the above dilemma needs to be

\footnotetext{
* Corresponding author.

E-mail address: berthiau@enstimac.fr (H. Berthiaux).
}

resolved. Chemical engineers, who have gone through an education scheme inherited from high-volume petrochemicals supplies, are naturally oriented towards the use of continuous processes. While the situation tends to change as explained by Roche et al. [1], they are still not sufficiently present in certain industrial sectors to gain enough leverage, or to let chemical engineering paradigms make their own way. This is particularly the case in the pharmaceutical industry, which is the domain of reference for any person dealing with powder mixing issues.

One of the main reason why such a change is now better envisioned than in the past lays in the great technological advances made over the past decade on sensors specifically able to monitor powder processes, as well as on the purely analytical part of each technique. NIR spectroscopy $[2,3,4]$, FT-Raman [5,6], NIR chemical imaging [7], image-processing techniques $[8,9]$ are indeed radically changing the perception an engineer can have on a mixing process: from partial and biased information to nearly absolute knowledge. That said, the amount of data produced by these techniques is usually extremely important, if not complete. The need is strong for advanced methodologies in data treatment that must be specific to a desired product property. As an example, for continuous powder mixing, the coefficient of variation of the distribution of sample compositions must be derived in real-time from the 
measurement, as well as the definition of its time variability at the outlet of the process. Transforming the available data into meaningful criteria is therefore a true challenge from a chemical engineering's perspective. It is also the first step that may open the doors to robust process control, which is one of the main concepts associated with continuous processing. But for this, a deep study of what is happening, and how it can be modelled, during the transitory operation of a mixer is necessary. Emptying or feeding the mixer as well as changing of dosage mode to feed the hoppers are current transitory phases that are very likely to occur during processing. Their impact on the homogeneity of mixtures can be strong, and may compromise the use of a continuous mixer [10].

Main published and recent scientific articles have been concerned with the effect of the operating conditions on the homogeneity of the mixtures at the outlet of continuous mixers, always at steady-state. In their study on screw mixers for pyrolysis applications, Kingston and Heindel $[11,12]$ investigated the effect of the rotation mode (counterrotating or co-rotating, down or up-pumping), as well as screw pitch and screw speed. They found optimum configurations so as to minimize the variance of the mixture. After their early work on the Gericke250 mixer reported by the works of Portillo et al. [13] or Vanarase et al. [14], Professor Muzzio's team investigated the effect of blade configuration, mass flow rate and impeller's speed on the Relative Standard Deviation (RSD) at the outlet of a GCG-70 Glatt continuous mixer, operating with a pharmaceutical particulate system [15]. They claimed an improvement of the mixtures' homogeneities with respect to other technologies with the same materials. Still in the pyrolysis field, Zhan et al. [16] recently studied the effect of mixer elements, falling height and mass flow in a CCSM static mixer. They encountered that there exists an optimum of the number of elements (e.g. 4 elements out of 6 ) driving to the best RSD. It is worth noting that we have found similar trends in an unpublished study some years ago. These authors also developed a Markov chain approach to predict the RSD. To what concerns the effect of flow properties, such as bulk density or cohesion, on mean residence time or axial dispersion, one can also refer to another paper by Vanarase et al. [17] as a first overview of a problem that is still at its prime. It is also clear that this subject may gain subsequent knowledge from modelling and simulation, as pointed out in the DEM study presented by Sarkar and Wassgren [18], or by Mizonov et al. [19] through Markov chain modelling.

Another side of continuous processing lays in the integration of the various concerned unit operations (mixing, granulation, roller compaction), as well as certain processing steps such as buffers into a global framework. While this subject has not yet entered its infancy, it is worth noting the effort provided by recent pharma-driven studies [20-21], especially in terms of process control and product quality. In particular, the importance of detecting and eliminating out of specification materials in the early stages of the process is outlined.

However, none of the above-mentioned studies have been dealing with the transitory dynamics of such technological systems, despite of their industrial significance. In our previous recent works [22,23], we investigated the transitory dynamics of bulk solids flow in a Gericke GCM500 continuous mixer, using single powders (no mixture). The transitory phases that correspond to mixer start, emptying, as well as step changes in inflow rates or rotational speeds, have been studied in terms of outflow rate and hold-up weight variations. Empirical correlations have been derived to represent these variations in the general frame of a non-homogeneous Markov chain. For more information about this type of modelling approach, one can read the review paper by Berthiaux and Mizonov [24].

In the present study, we will consider mixtures of particles of different nature processed in the same equipment, and for which an on-line image analysis technique has been developed, as well as a specific data treatment methodology to derive a mixture's homogeneity criterion. Effect, on this criterion, of the scale of scrutiny of the mixture, as well as the rotational speed of the stirrer and strong perturbations will be reported and discussed.

\section{Experimental set-ups and methods}

\subsection{Powders used}

Our goal is to study the mixer, to gather data on the mixing process, not to process a specific powder or mixture through it. Therefore, we have chosen commercial, cheap, products for which the composition of the mixtures formed can be analyzed in a routine way. Couscous particles are of nearly spherical shape and are available in specific size ranges as they process from humidification of wheat, agglomeration, vapor heating, drying and calibration. Here, we will use coarse and fine fractions of couscous, the main physical properties of which can be found in Table 1.

Coarse couscous has been pre-sieved, so that there is no overlap of the distributions, allowing an easy separation of the components by sieving, and further recycling of the products for various sets of experiments. Both distributions demonstrate a small and identical value of the span, meaning that we will practically deal with a binary monodisperse system that may be able to segregate [25]. The density values are nearly identical, meaning in turn that density segregation is unlikely to happen. Finally, the comparison of the compressibility indexes (Carr and Hausner ratios) built from apparent densities, shows that both systems are free-flowing, so once again, segregation may be feared.

Fine couscous particles have been colored in black by an iodine adsorption procedure that has been described in previous works [26]. This will allow the further calculation of compositions through image capture and analysis.

\subsection{Mixer studied and image capture system}

The Gericke GCM500 continuous mixing system (Fig. 1a) has been under investigation by our research team since a decade. RTD experiments have been reported and published [27], as well as homogeneous Markov chain modelling of mixers [28], hold-up weight prediction and influence of stirrer speed [29] or type [30], always at steady-state.

The system is equipped with two loss-in-weight feeders in order to feed the mixing section with precision and regularity. The mixer itself is a hemi-cylindrical tank of $50 \mathrm{~cm}$ long, $16.5 \mathrm{~cm}$ height and $20 \mathrm{~cm}$ diameter. The motion of the particles is due to the action of a frame (Fig. 1b) which is constituted of rectangular blades ensuring a radial dispersion of the particles inside the vessel. A sort of "screw", which is placed inside the frame, serves to the transportation of the powder in the axial direction. The rotational speed $\mathrm{N}$ of the stirrer is expressed in terms of frequency and will be set to $10,20,30,40$ or $50 \mathrm{~Hz}$ in this study. Because of the stirrer's design that favors axial particle flow, higher frequencies are not viable in process terms as they lead to the total emptying of the mixer when equipped with this type of stirrer.

A variable speed conveyor belt of $30 \mathrm{~cm}$ width is placed at the outlet of the mixer, so that the whole volume of the mixture produced is directly transposed into a 2D mixture. A linear CCD camera (one pixel width -5000 pixels length) is placed vertically with respect to the

Table 1

Main physical characteristics of the powders used: particle sizes are measured by sieving, apparent densities by Erweka "tap-tap" volumenometer, true density by He pycnometer.

\begin{tabular}{lll}
\hline Considered property & Coarse couscous & Fine couscous \\
\hline $\mathrm{d}_{10}(\mu \mathrm{m})$ & 1375 & 680 \\
$\mathrm{~d}_{50}(\mu \mathrm{m})$ & 1700 & 860 \\
$\mathrm{~d}_{90}(\mu \mathrm{m})$ & 1970 & 980 \\
$\left(\mathrm{~d}_{90}-\mathrm{d}_{10}\right) / 2 * \mathrm{~d}_{50}$ & 0.175 & 0.170 \\
True density $\rho\left(\mathrm{kg} \cdot \mathrm{m}^{-3}\right)$ & 1452 & 1442 \\
Aerated apparent density & 762 & 759 \\
$\rho_{\mathrm{a}}\left(\mathrm{g} \cdot \mathrm{m}^{-3}\right)$ & & \\
Tapped apparent density & 779 & 787 \\
$\rho_{\mathrm{t}}\left(\mathrm{kg} \cdot \mathrm{m}^{-3}\right)$ & & \\
Carr index: $100 *\left(\rho_{\mathrm{t}}-\rho_{\mathrm{a}}\right) / \rho_{\mathrm{t}}$ & 2.22 & 3.60 \\
Hausner ratio: $\rho_{\mathrm{t}} / \rho_{\mathrm{a}}$ & 1.02 & 1.04 \\
\hline
\end{tabular}


a

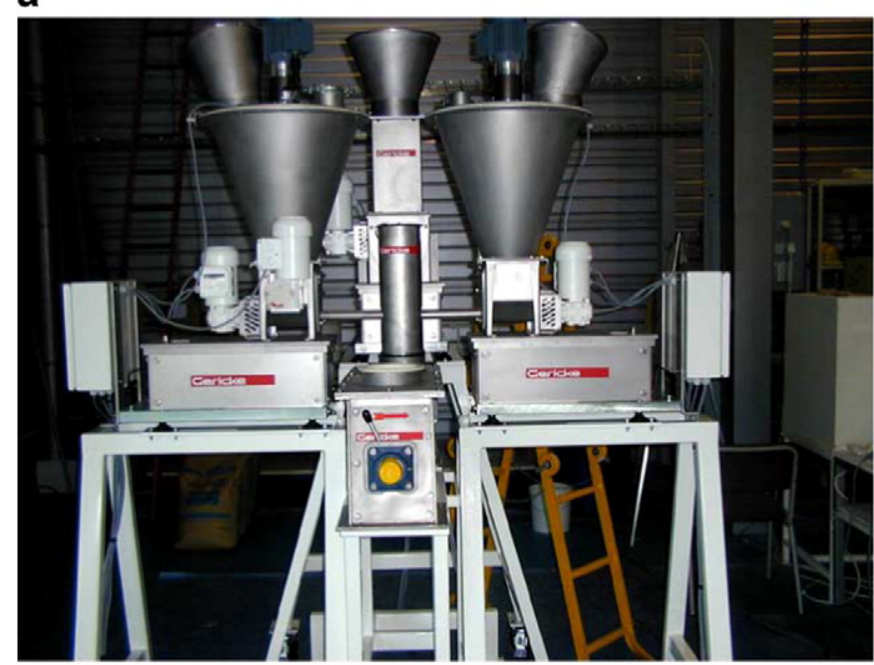

b

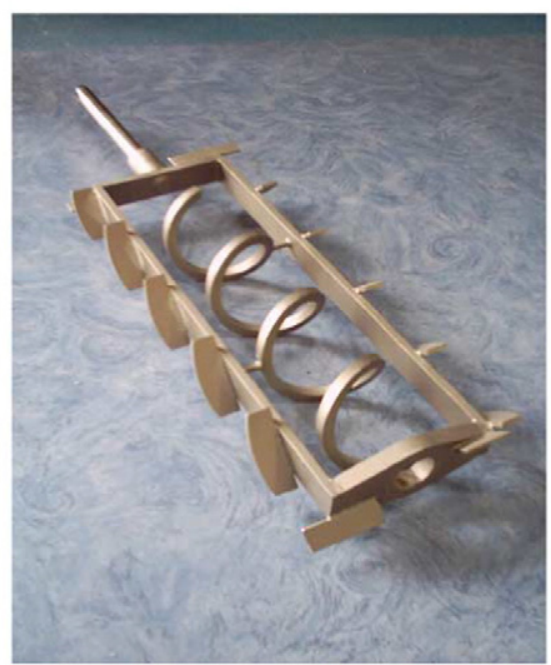

Fig. 1. (a) - GCM500 mixing system including loss-in-weight feeders, inlet chute, mixer body ; (b) - Stirrer type used in the present study showing the frame supporting the blades and the internal transport screw. belt and films the mixture as it passes under it (Fig. 2). A powerful lighting system composed by two lamps diffusing a white light is placed at each side of the camera. This standardizes the illumination of the surface of interest, which becomes insensible to outdoor light. More insight on this set-up can be found in a previous study (Demeyre [31]).

Each pixel represents a $60 * 60 \mu \mathrm{m}^{2}$ surface on the belt, which is much smaller than the size of any of the particles involved. By grouping 200 consecutive one-pixel-width lines, it gives rise to a $500 * 200$ pixel $^{2}$ image (or $30 * 1.2 \mathrm{~cm}^{2}$ surface). The camera's speed being of 14 images per second, the mixture's film speed is finally of $16.8 \mathrm{~cm} \cdot \mathrm{s}^{-1}$. This same value will therefore be imposed to the belt's linear speed. At that speed, a single-particle layer is formed on the belt, allowing the counting of every single particle of the mixture.

This system is connected to a computer equipped with an Imaq1408 card, which allows the time-continuous acquisition of the images. Each image is transferred into a buffer memory in the computer before being erased by the following image. In the meantime, the image is extracted and treated by the Labview ${ }^{\circledR}$ software and its IMAQ Vision library. This confers to each pixel a value comprised between 0 (black) and 255 (white). An additional threshold procedure has also been employed to eliminate the color of the belt (green) from the images. This procedure has been calibrated thanks to partially colored white sheets placed on the belt, as well as particulate systems of known compositions. Other validations protocols -not reported here- have been undertaken. They confirm that the surface measurement is equivalent to the mass measurement, and that the compositions measured on-line are similar to those obtained by off-line sieving.

\subsection{Sample definition and homogeneity calculation}

When evaluating the homogeneity of a mixture, a scale of scrutiny must be defined in relation with the end-user properties that are targeted. In the present case, the minimal scale of scrutiny is that of the elementary images that are stored and analyzed, and will depend on the outflow rate of the mixer. When the total flow rate is fixed at $40 \mathrm{~kg} \cdot \mathrm{h}^{-1}\left(11.11 \mathrm{~g} \cdot \mathrm{s}^{-1}\right)$, and as the camera captures 14 images per second of the single-layer bed, the mean powder mass contained in an elementary sample will be $794 \mathrm{mg}$. Elementary samples can be grouped together in order to build samples of bigger sizes as it can be seen in Table 2 . If the scale of scrutiny is smaller than size 1 , the homogeneity of the mixture will be over-estimated, which is a risky situation. Conversely, if a too small sample size is considered in a mixture's homogeneity evaluation, it will give rise to an over-quality situation.

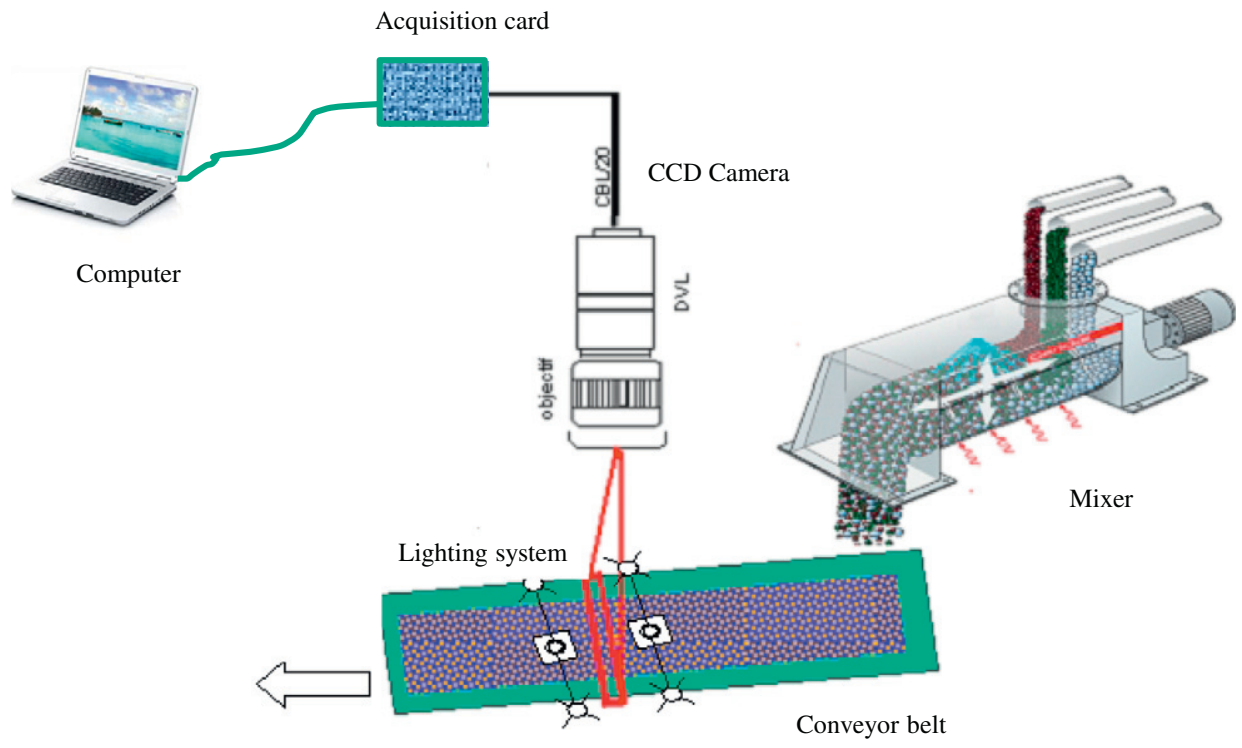

Fig. 2. System used for transfer of the mixture into a conveyor belt and image capture. 
Table 2

Relation between sample size, sample mass and number of images, for a reference of $40 \mathrm{~kg} \cdot \mathrm{h}^{-1}$ outflow rate.

\begin{tabular}{lll}
\hline Sample size & Number of images & Sample mass $(\mathrm{g})$ \\
\hline 1 & 1 & 0.794 \\
2 & 7 & 5.500 \\
3 & 14 & 11.110 \\
4 & 21 & 17.776 \\
\hline
\end{tabular}

Once a key ingredient of a mixture has been defined, mixture homogeneity is usually quantified by the segregation intensity $\sigma^{2}$, which is the variance of the distribution of the compositions of the $\mathrm{N}$ samples of a whole mixture, $\mu$ being the mean composition and $x_{i}$ the composition in sample i:

$\sigma^{2}=\frac{1}{N} \sum_{i=1}^{N}\left(x_{i}-\mu\right)^{2}$

In the case of complete segregation, as at the mixer's inlet, the variance reduces to:

$\sigma_{0}^{2}=(1-\mu) \mu$

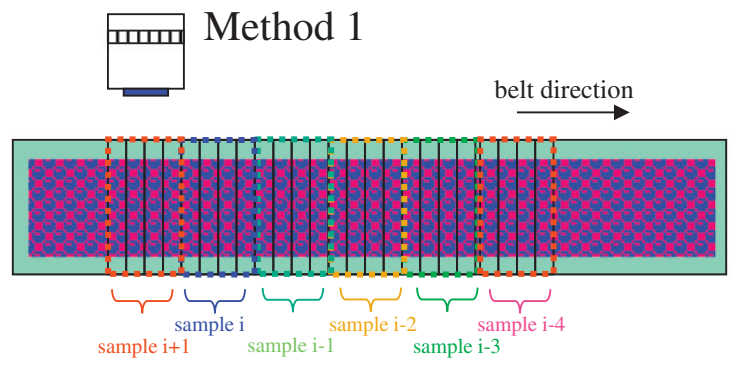

Fig. 3. Sampling methodologies considered in the study (left: method 1, right: method 2).

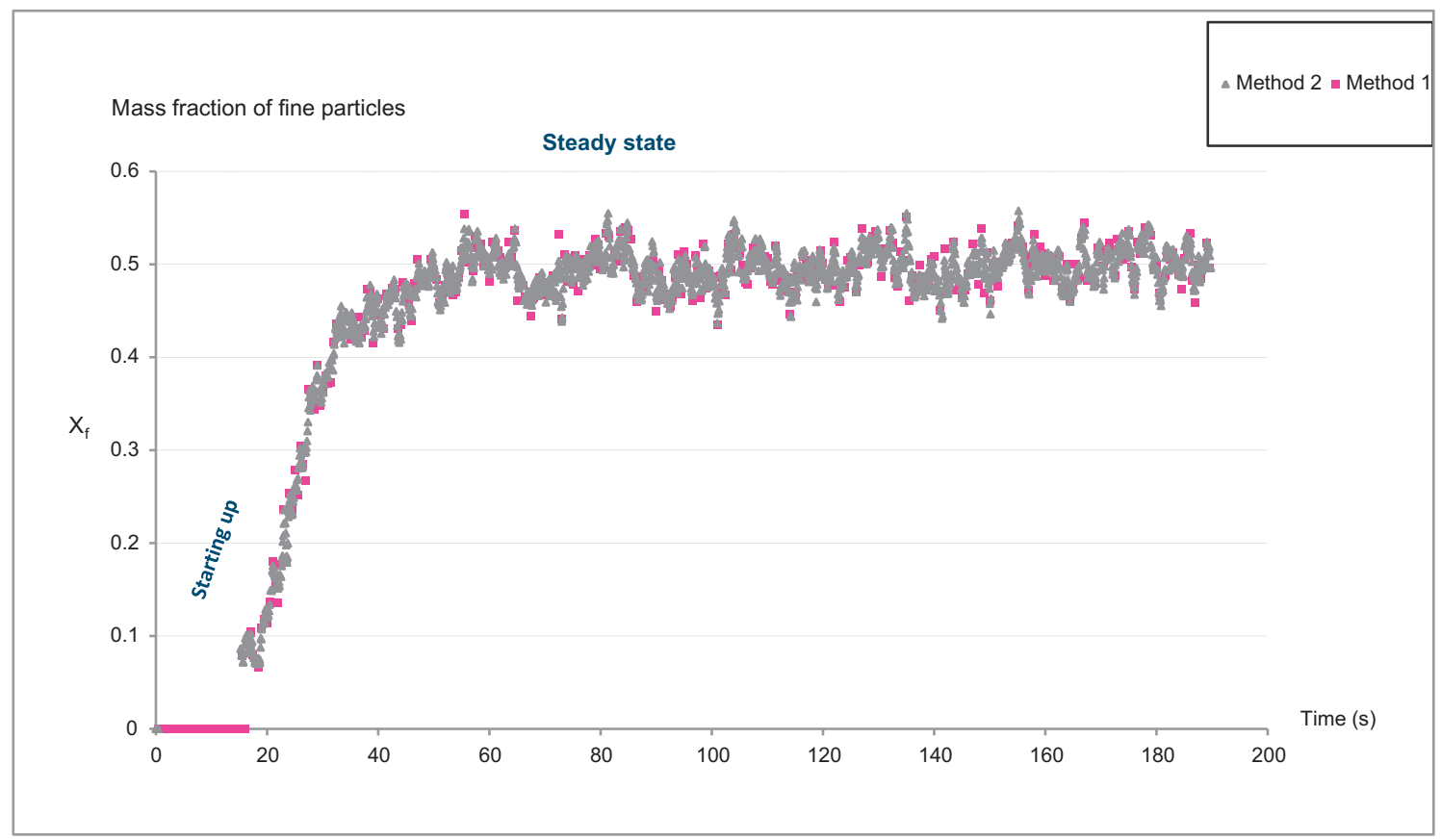

Fig. 4. Comparison between method 1 (in pink, sample slide) and method 2 (in grey, elementary sample slide) during mixer's start and steady-state operation. Rotational stirrer's speed is $40 \mathrm{~Hz}$, inflow rate $40 \mathrm{~kg} \cdot \mathrm{h}^{-1}, 50-50$ mixture. $\mathrm{X}_{\mathrm{f}}$ is the mass fraction of the fine particles.

As it allows to link the standard deviation to the value of the mean composition, the coefficient of variation $\mathrm{CV}$ is more than often used in the industry:

$C V=\frac{\sigma}{\mu}$

For more information on the characterization of powder mixtures, one may refer to Harnby [32].

In continuous mixing, the homogeneity of a mixture is defined at the outlet of a mixing process, and is due to the ability of the mixer to attenuate the fluctuations in composition caused by the feeding system [33]. It must be conceptualized by considering a series, a "window", of n consecutive elementary samples taken at the outlet of the mixer and further calculation of the variance $\sigma^{2}$ that is attached to these $\mathrm{n}$ samples. The time evolution of $\sigma_{n}^{2}$ provides an idea of the fluctuations in the homogeneity of the mixture that is due to those of the feeding system. For example, a change of dosage mode due to the filling of a hopper, will be detected by a rise in $\sigma_{n}^{2}$ that may drive to an out-of-specification situation. Two methodological strategies can be defined when analyzing the variations of $\sigma_{\mathrm{n}}^{2}$ :

- Sample sliding method (method 1). In this case, the window of observation slides at every sample, which means that we have to wait for $n$ elementary samples to build the next value of the variance (see Fig. 3).

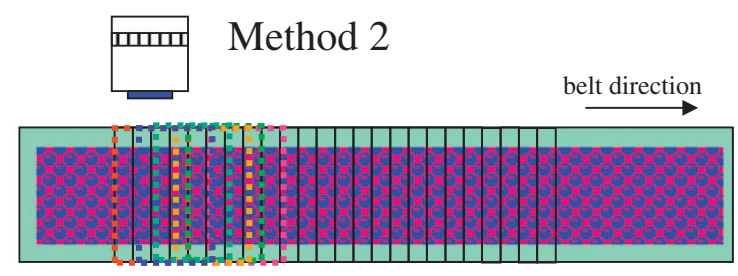




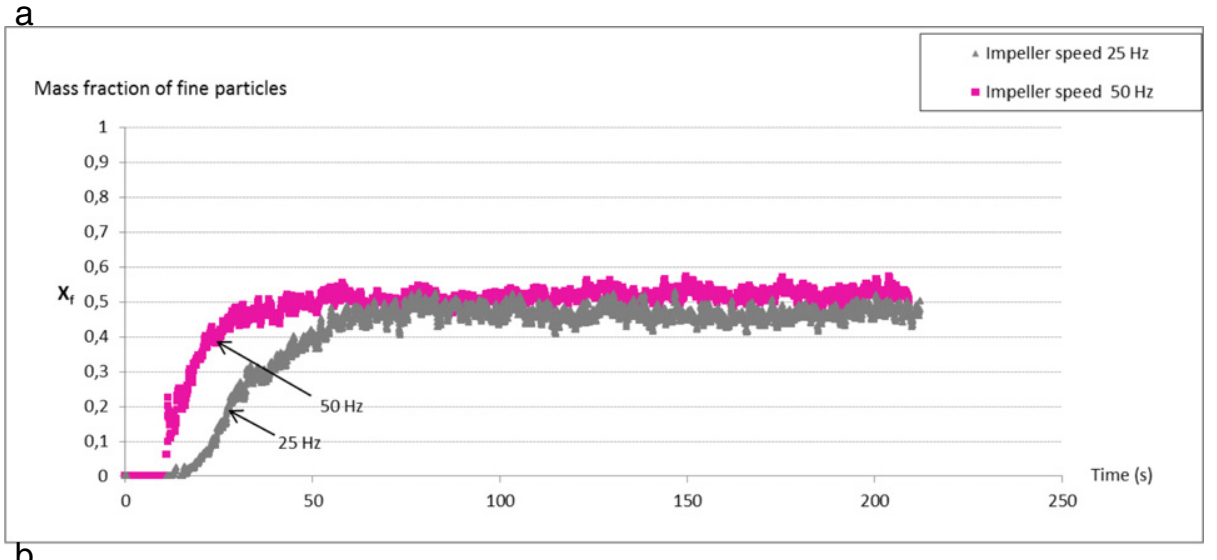

b
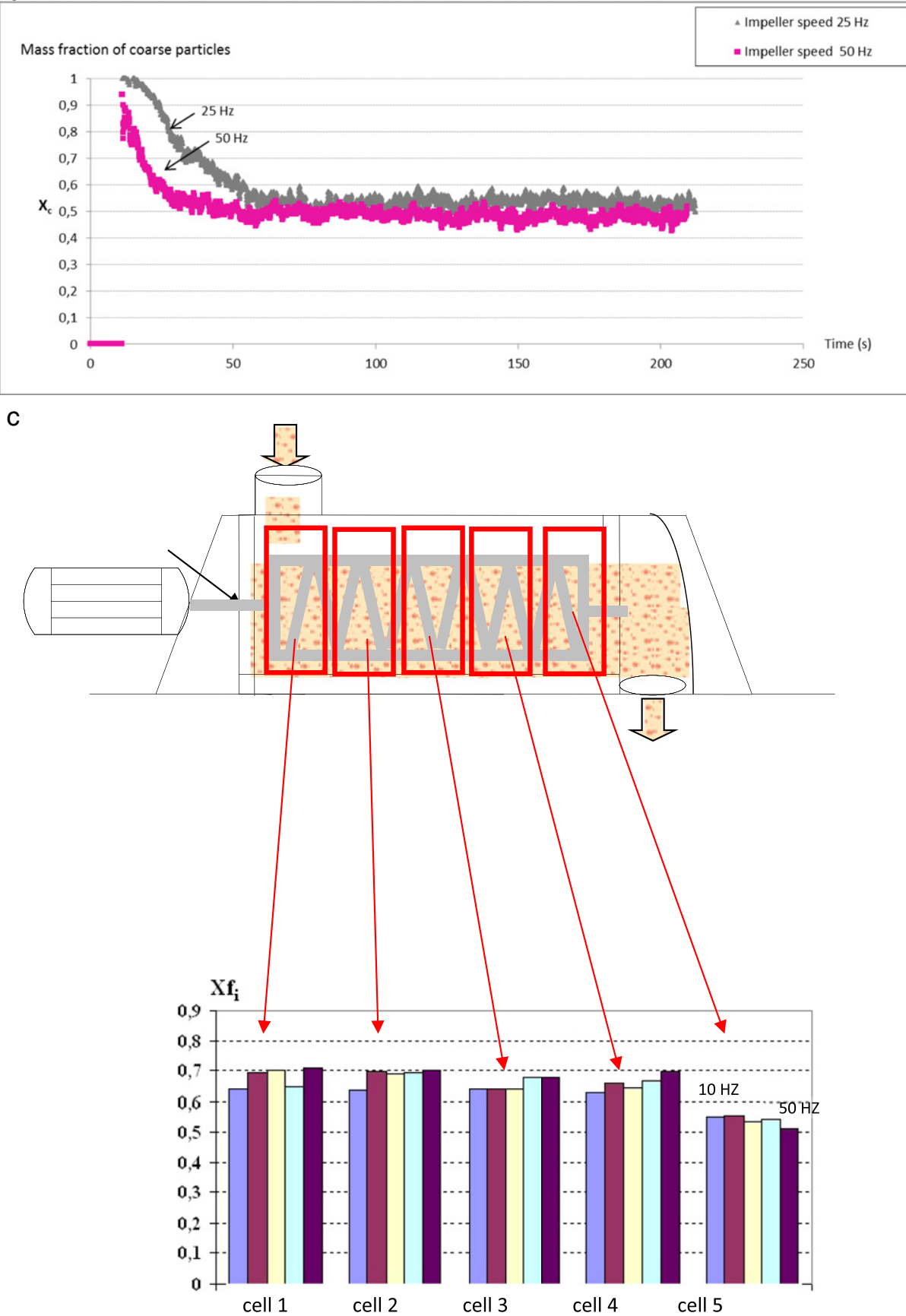

Fig. 5. Coarse (a) and fine (b) particle contents as measured at the outlet of the mixer during starting and at steady-state (mixture A, sample size 2) in the conditions indicated; (c) definition of 5 cells in the mixer and analysis of their contents at steady-state. 
a

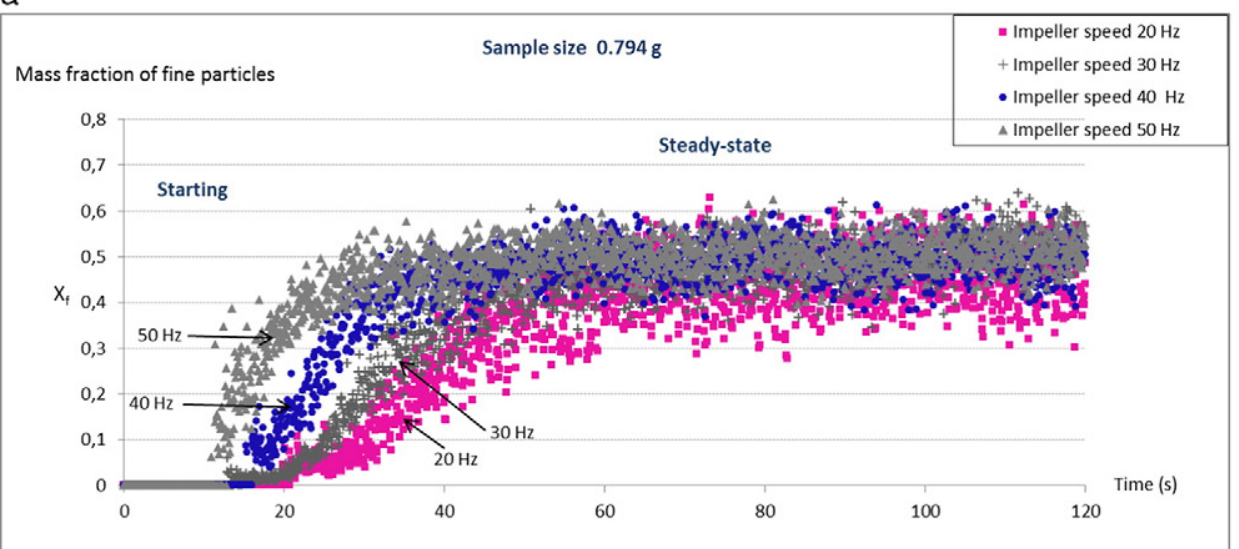

b
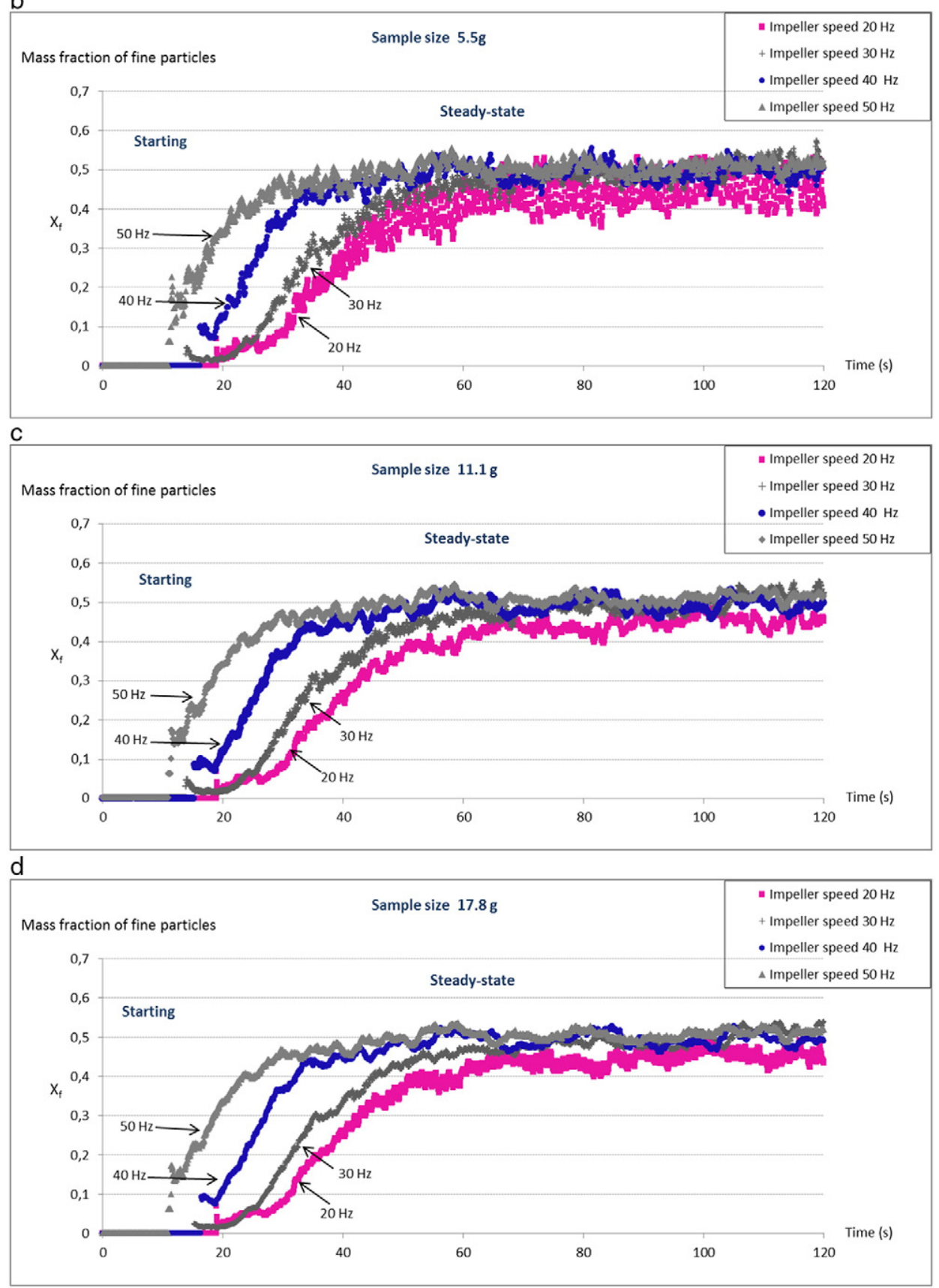

Fig. 6. Effect of the scale of scrutiny of the mixture (sample size) in the evaluation of fine particle contents (mixture A) in the conditions indicated in the graphs. 
- Elementary sample sliding method (method 2). The window of observation slides by the "width" of a single elementary sample at each time. Although this procedure is supposed to give rise to a smoother curve, the sampling error may rise due to the increase of the number of boundaries involved [34].

Fig. 4 shows an example of comparison between the two methods for the case of size 2 samples (7 elementary samples). The signal
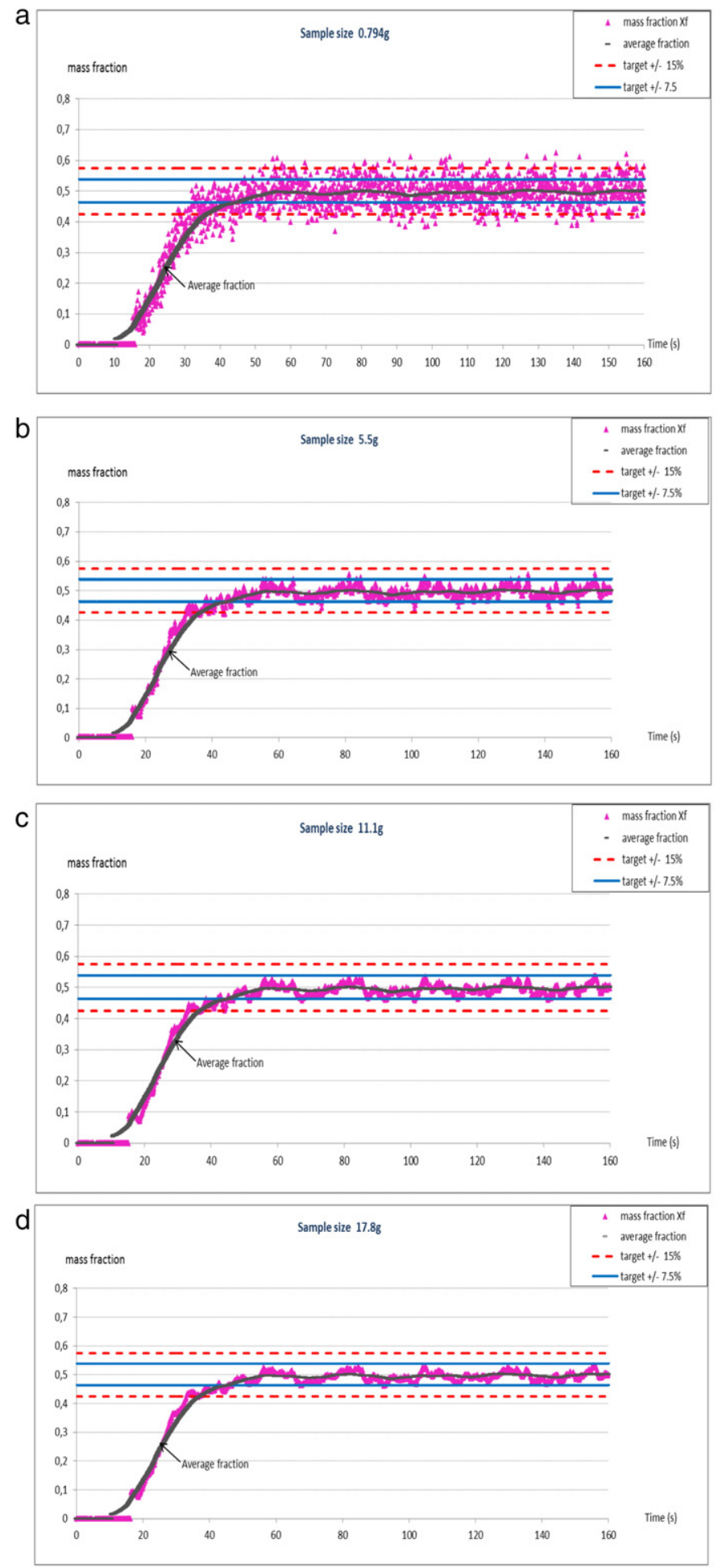

given by method 2 is almost continuous with time and will be employed in the present study. In addition, it has been proven to be more able to detect small defects in the mixture [35].

\section{Results and discussion}

Two mixture compositions have been under investigation, namely a $50-50 \%$ by weight $(A)$ and a $12.5-87.5 \%$ by weight $(B)$ mixture of coarse
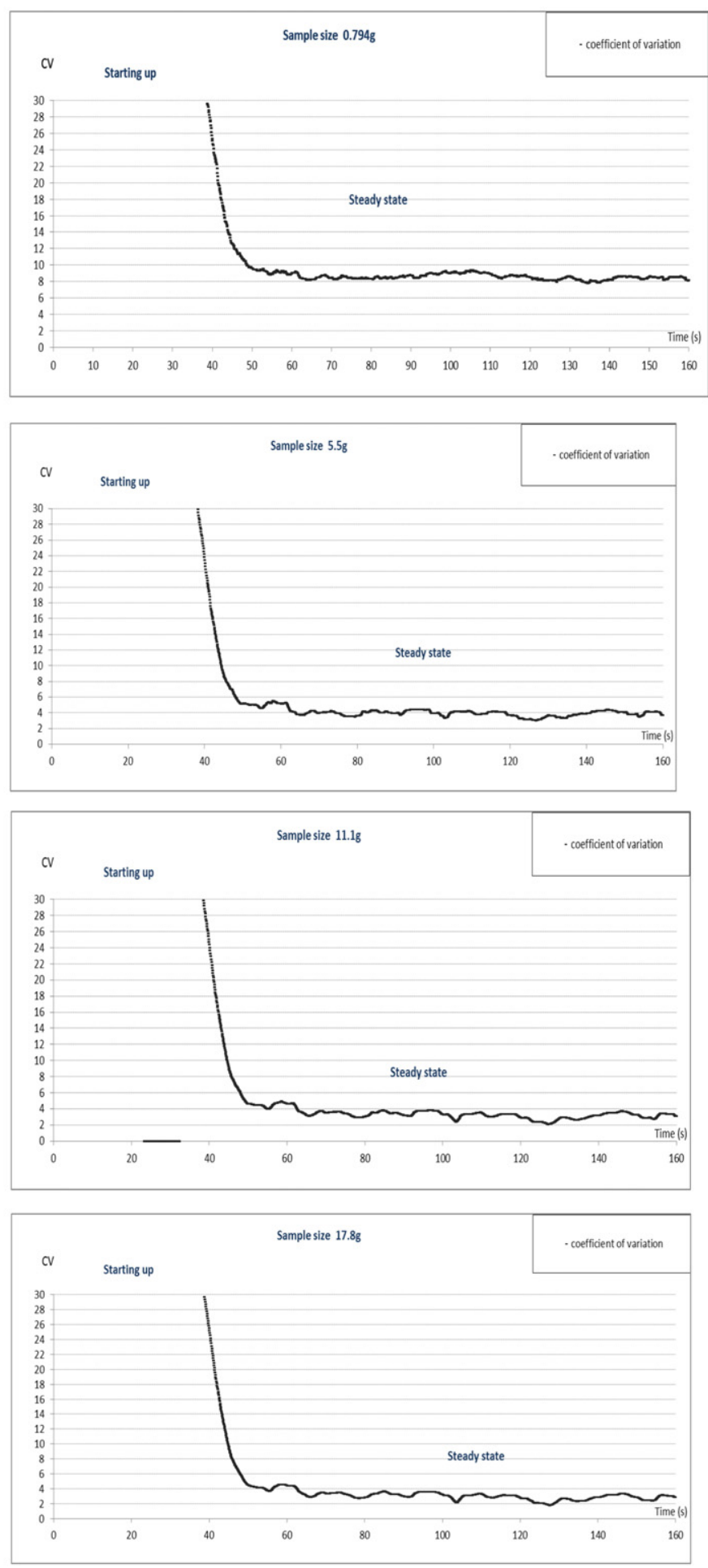

Fig. 7. Time-evolution of fine fraction contents measured at the mixer's outlet (left) and mixture CV's (right) for different sample sizes (a, b, c, d). Results obtained for mixture A processed at $40 \mathrm{~kg} \cdot \mathrm{h}^{-1}$ and $\mathrm{N}=40 \mathrm{~Hz}$ 
and fine couscous respectively. While fine particles are less represented in weight in mixture B, they are still in majority in terms of number of particles. In the following, we will first examine the existence of a segregation phenomenon that takes place inside the mixer, we will further discuss the importance of the scale of scrutiny in the appreciation of these mixtures, as well as the effect of the rotational speed of the impeller on their quality. We will finally focus on the significance of step perturbations in rotational speed and examine if a change in impeller's speed can be done without stopping the mixing process.

\subsection{Evidence of particle size segregation inside the mixer}

Fig. 5a and $\mathrm{b}$ shows the time-evolution of both fine and coarse mass fractions of mixture A, seen at a scale of scrutiny corresponding to size 2 , for two different rotational speeds of the stirrer. At steady-state, the composition measured is obviously that of the inlet composition (50\% in both components). But surprisingly during the transitory starting regime, the composition of the mixture is far from the nominal one. The first particles that are flowing out of the mixer are essentially coarse particles, as the fine fraction equals 0 . The content in fine particles in the outlet mixture rises then, so as to reach the steady composition of $50 \%$. The content in coarse particles does exactly the reverse process. The mass balance needing to be held true, this means that fine particles have been accumulating inside the mixer during the starting period. Being size the only difference between the two types of particles, it can be said that particle size segregation has occurred, as was "feared" when characterizing the particulate systems. It can also be seen that an increase in stirrer's rotational speed drives to a smaller transitory period, meaning that the portion of the out-of-specification period of time can be reduced by doing so.

This result is confirmed in Fig. $5 c$, for which the content of the mixer has been analyzed after stopping the process once it has reach steadystate. To have a better insight, five compartments -or cells- of identical volumes have been defined and sieved to gather the fine particles. The fine particles contents of cells 1 to 4 , those who are closer to the mixer's inlet, are in the range $60-70 \%$, with a slight dependence on impeller's speed. Cell 5 , which is the compartment just before the outlet, shows a fine content close to the nominal $50 \%$. In other words, the last part of the mixer is "delivering" the right mixture to the outlet. The same behavior has been found for mixture B, while it is not reported here. For this mixture, it is worth noting that cells 1 to 4 showed fine particle contents in the range $25-30 \%$, cell 5 getting closer to the nominal value (12.5\%).

Because of the collision-driven flow regime inside the mixer, we can assume that segregation is due to the famous "Brazil nuts effect" that has been widely commented in the literature over the years [36-38]. During the starting period that corresponds to the mixer's filling and because of the size difference that makes small particles sifting between coarse particles, coarse particles are somewhat "floating" at the top of the bed. As a result of this percolation mechanism, coarse particles are the only particles that are exiting the mixer first. At this moment, the bed structure is probably made of fine particles at its bottom, and layers of the mixture getting richer and richer in coarse particles at its top. But as the feeders are still delivering a 50-50 composition and being the bed structure formed, the particles entering the mixer afterwards may practically slide at the surface of the bed and exit the mixture at the right composition. Unfortunately, neither horizontal sampling nor sample thief sampling were possible in our case, so this will remain at the stage of a possible explanation of this astonishing system's dynamic phenomenon.

By the way, this still poses an issue concerning the efficiency of the mixer or impeller design that is unable to counter this segregation effect, and may be at the source of it. In addition, the answer of this system when subjected to even small flowrate or impeller speed perturbations may be feared in terms of its ability to reach a steady-state.

\subsection{Scale of scrutiny effect}

Fig. 6 shows the effect of the sample's size on the fine particle fraction, as measured at the outlet of the mixer, for mixture A. For the smallest size considered in this study (approximately $800 \mathrm{mg}$ ), it can be seen that the fluctuations around the mean value are of high amplitudes in the transitory (starting) regime and in the steady-state regime as well. Individual values are fluctuating in the range $40-60 \%$, with some points below $30 \%$ and others higher than $65 \%$. If this scale of scrutiny needed to be adopted in an industrial context, this mixture would be out-of-specification, as some individual values are out of the range $[-15 \% \mu ;+15 \% \mu]$. In addition, it does not seem that an influence of the impeller speed on the extent of these fluctuations really exists.

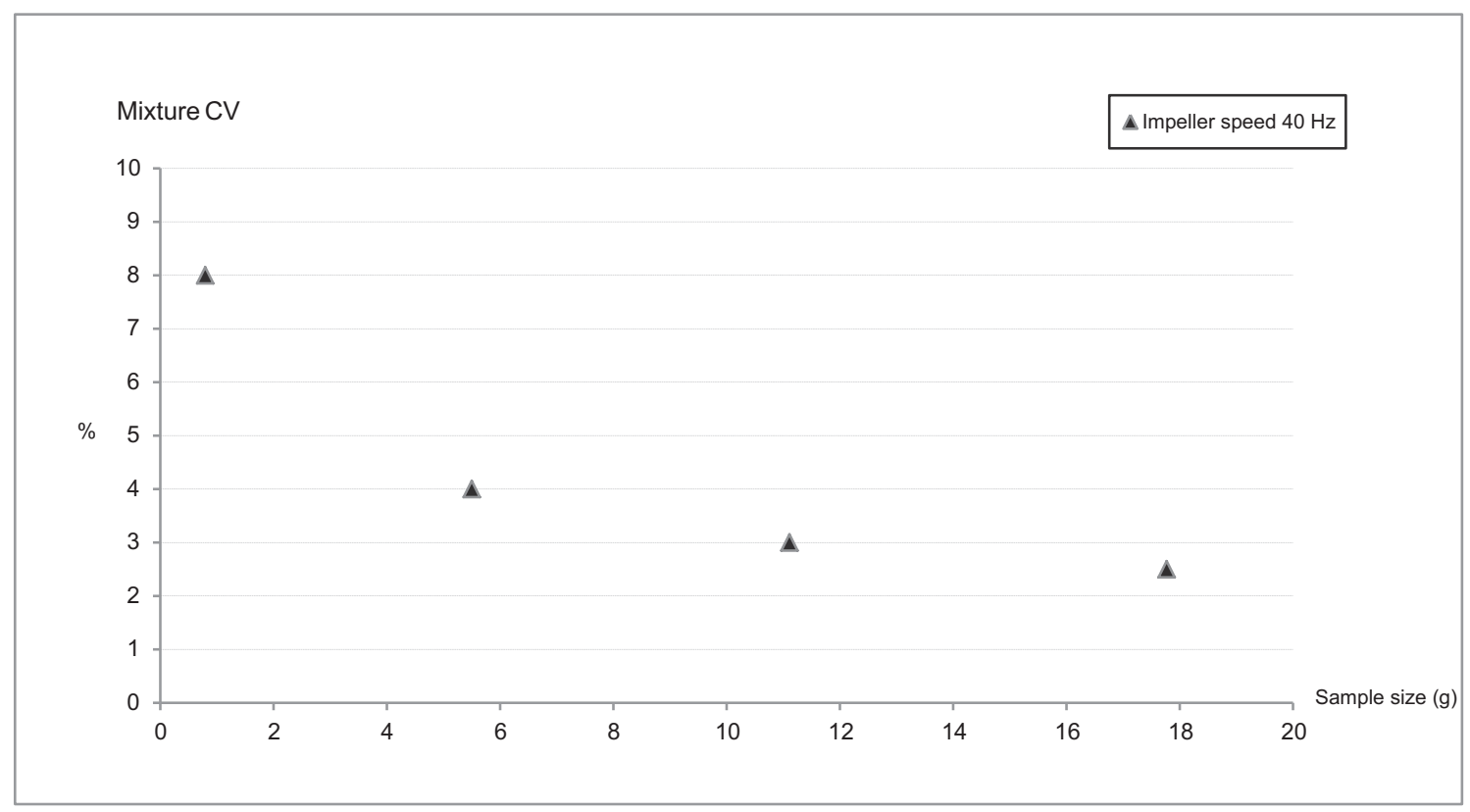

Fig. 8. Dependence on the CV measured on the sample mass (or scale of scrutiny). 

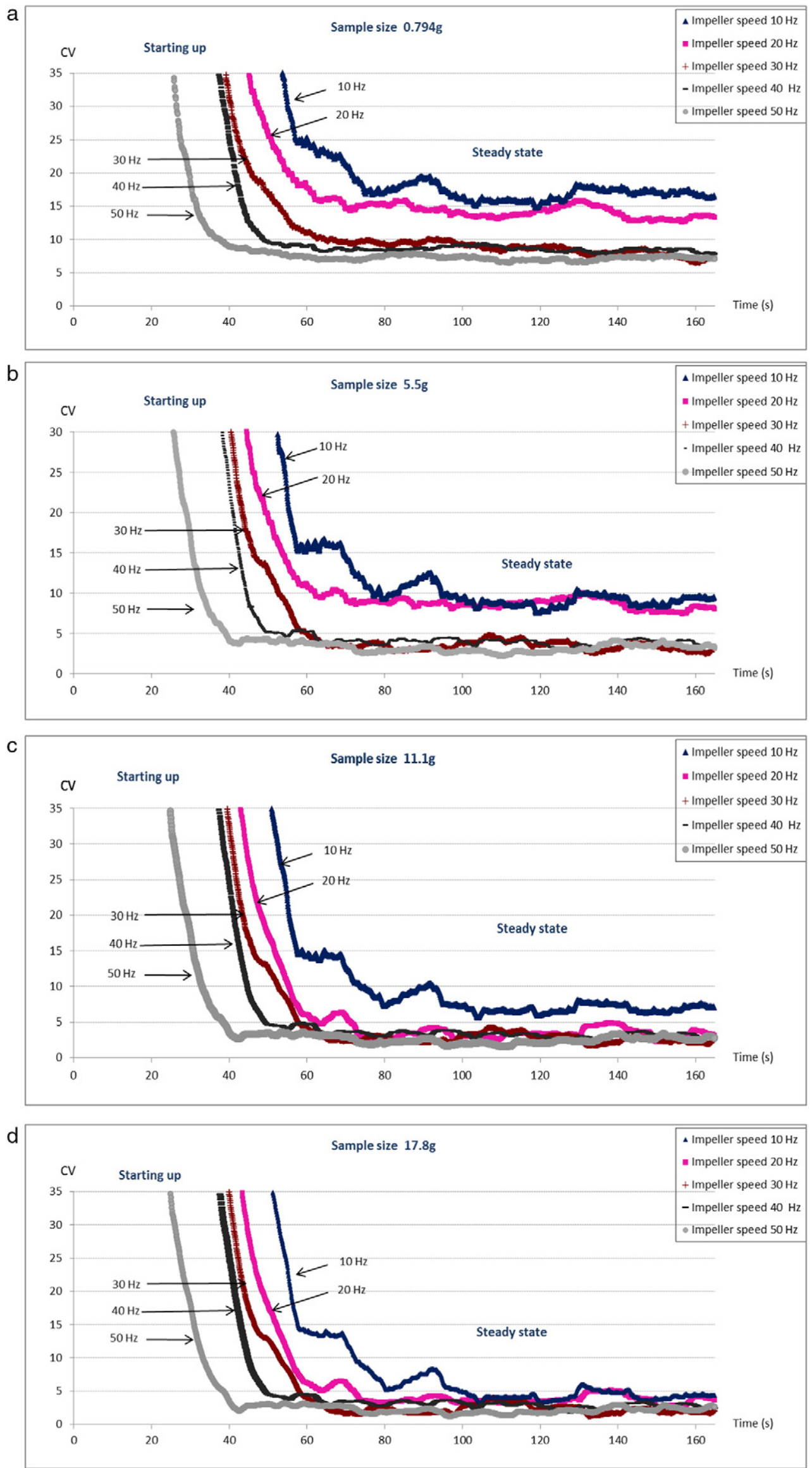

Fig. 9. Time-evolution of mixture A CV's for different sample sizes and for different impeller speeds (a-d). 
a
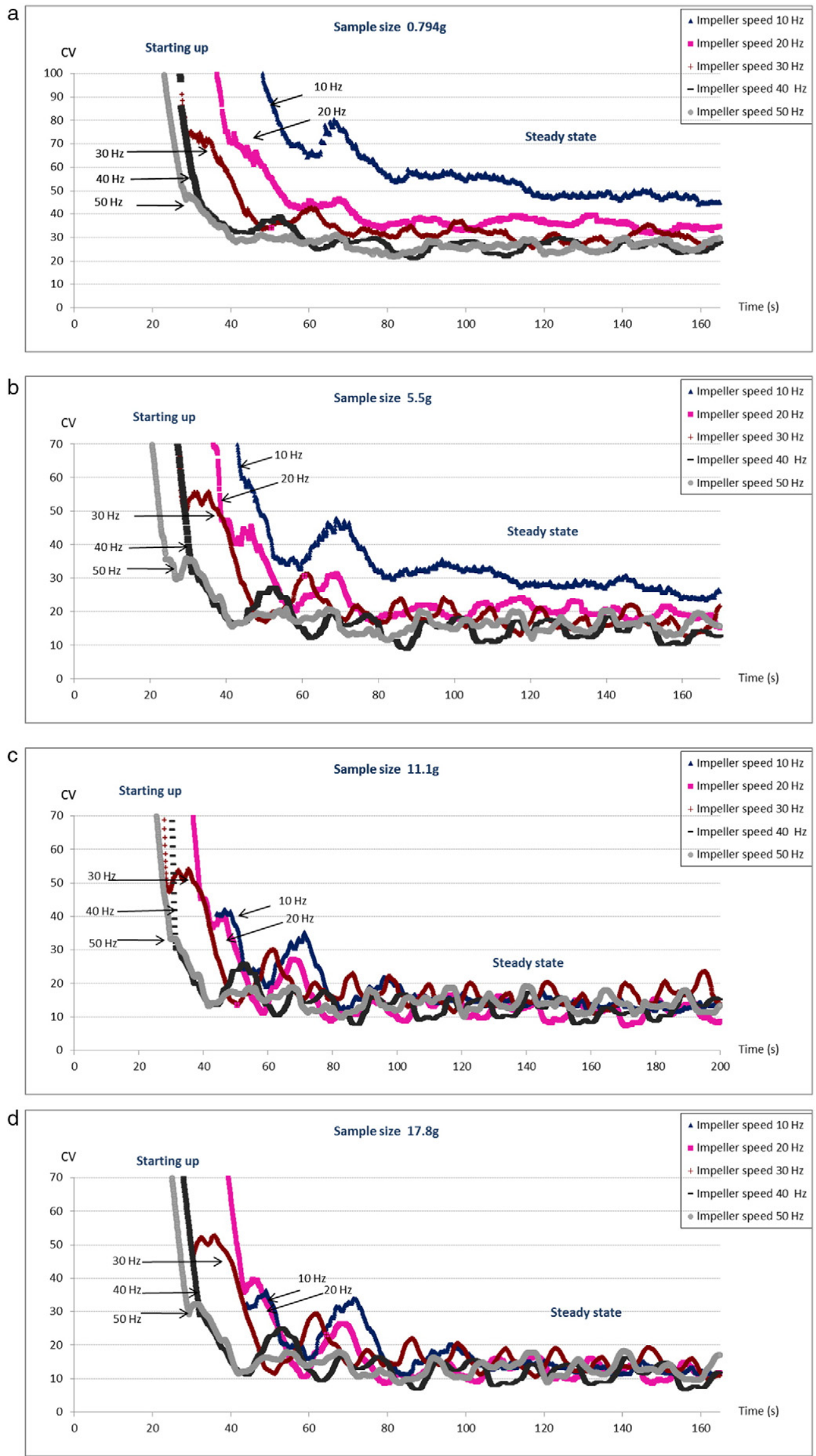

Fig. 10. Time-evolution of mixture B CV's for different sample sizes and for different impeller speeds (a-d). 
When increasing sample size, which means observing the mixture at a higher scale, those fluctuations are decreasing in terms of amplitude. For size 2 , fluctuations are in the range $42-58 \%$ with some points at $35 \%$ and others at $60 \%$. For size 3 (fourteen times size 1 ), they stay in the range $45-55 \%$ with individual values at $41 \%$ and $58 \%$. Finally, for size 4 , fluctuations are reduced to a $47-53 \%$ range, with the existence of individual values comparable to those of size 3. As known, the increase of scale drives to a smoother signal, but also to the impossibility to detect small scale heterogeneities.

In Fig. 7, the corresponding coefficients of variations have been plotted against time, the impeller speed being set to a value $N=40 \mathrm{~Hz}$, while the inflow rate was equal to $40 \mathrm{~kg} \cdot \mathrm{h}^{-1}$. The strong perturbations evidenced for size 1 can be appreciated in the $\mathrm{CV}$, once it reached a steady value close to $8 \%$. Industrial standards for CV values are usually below $6 \%$, which means that this mixture would definitely never pass a release-to-the-market protocol. The decrease of the steady CV with the other sample sizes can be observed in Fig. 8. The behavior is absolutely not linear, which means that increasing the scale to reach a better mixture evaluation would be an extremely dangerous task. Indeed, the evaluation of the homogeneity of a mixture cannot be dissociated from a proper definition of the scale at which the mixture must be evaluated. It is worth noting that in most industrial mixing cases encountered by our research team over the years, the scale of scrutiny -that of the end-user properties- was not known, and had to be defined on the basis of thoughts rather than facts.

\subsection{Impeller rotational speed effect}

The rotational speed of the stirrer, as well as its design, is known to be the main factor affecting the homogeneity of a mixture. In Fig. 9(a-d), the effect on the evolution of the CV at the outlet of the mixer can be appreciated, for mixture A. First, it can be denoted that the transitory period corresponding to the start of the mixer is all the more reduced that the impeller speed is high. This is important in an industrial perspective as the period of production corresponding to mixer's start may have to be disregarded because of out-of-
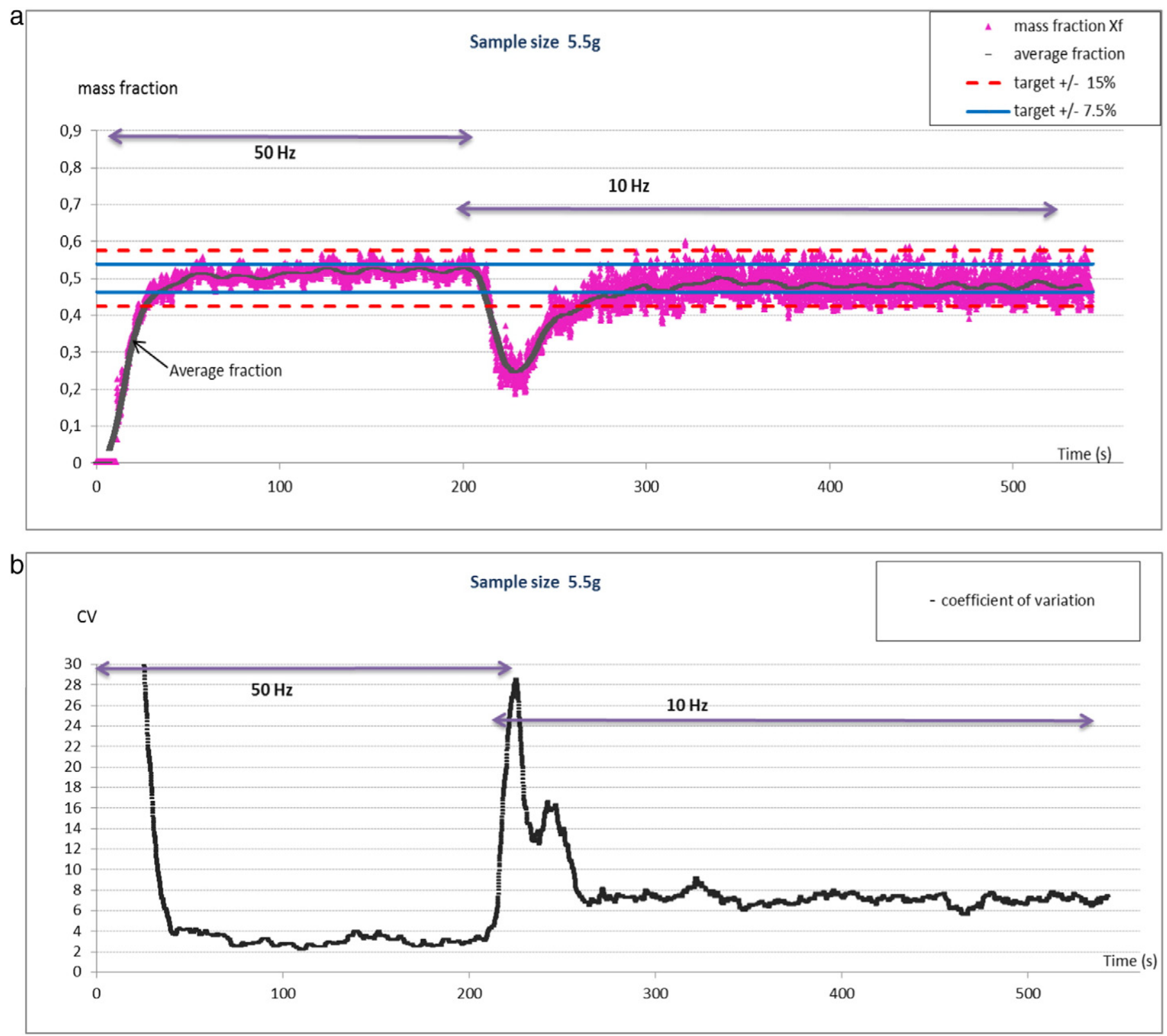

Fig. 11. Effect of a negative step $(50 \mathrm{~Hz}-10 \mathrm{~Hz})$ of the impeller speed on fine fraction values (a) and mixture's CV (b). Results given for mixture $\mathrm{A}$ at a flowrate of $40 \mathrm{~kg} \cdot \mathrm{h}^{-1}$ and a scale of scrutiny corresponding to size 2 . 
specification issues. It also emphasizes the idea that the transitory period may preferably be driven at high speed, before setting this speed at the desired value. In the results presented here, all the curves are presenting the same decreasing shape, afterwards the CV stabilizes at a steady-state value.

For the smallest scale of scrutiny, two impeller speed regimes can be defined that drive to two different values of the steady-state CV. Up to $20 \mathrm{~Hz}$, the CV is roughly equal to 15 , which corresponds to a bad mixture case, while above $30 \mathrm{~Hz}$, the CV lays between 7 and 8 . For size 2, the CV jumps from 8 for speeds up to $20 \mathrm{~Hz}$ to $3-4$ above $30 \mathrm{~Hz}$. In this case, the mixture reaches typical industrial standards of acceptance. This may be explained by the fact that, as the powder bed is getting much smaller (see [10]), the dispersion of the particles becomes easier than at small speeds. At the biggest sample size, the small scale heterogeneities are almost completely hidden by the magnification of the scale of scrutiny, and the bad mixture detected above looks like acceptable.

Results concerning mixture B are represented in Fig. 10(a-d). As for mixture A, high impeller speeds allow to reduce the CV during the transitory phase. The same conclusion can be stated about the influence of the impeller speed on the steady-state $\mathrm{CV}$, when examining the results obtained for small size samples. Steady-state CV values are all -and by far- superior to the $6 \%$ standard, and in some cases between five and eight times this value. For a given impeller speed and scale of scrutiny, it can be said that fluctuations observed in mixture $B$ are much more significant than for mixture $A$. This is not surprising since the minor (in weight \%) component in mixture B is the one for which those fluctuations are calculated.

\subsection{Effect of strong perturbations on mixture quality}

While a continuous process is normally conceived to be operated at steady-state, it is in practice subjected to multiple transitory periods while processing. This occur during the start and stop phases of the mixer itself, the hopper's filling phases for which feeders provide flowrates of low regularity, micro-stops that can be due to changes in parts (compression parts for example), etc. We have yet commented this some years ago [18], and draw the attention to the fact that it may be better to stop the mixer while filling hoppers. In addition, in the objective of process control, control of the mixer by adjusting a process variable, such as impeller speed, will give rise to transitory periods

a

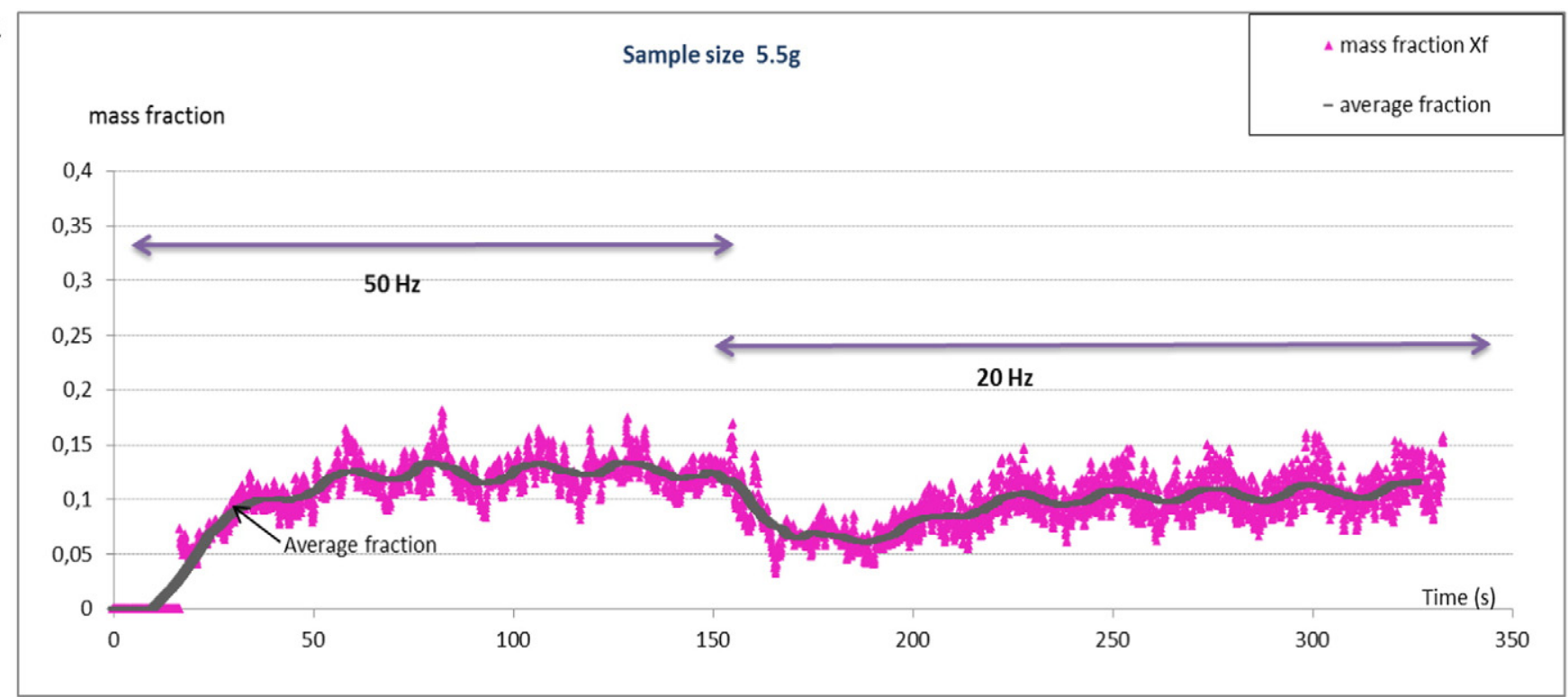

b

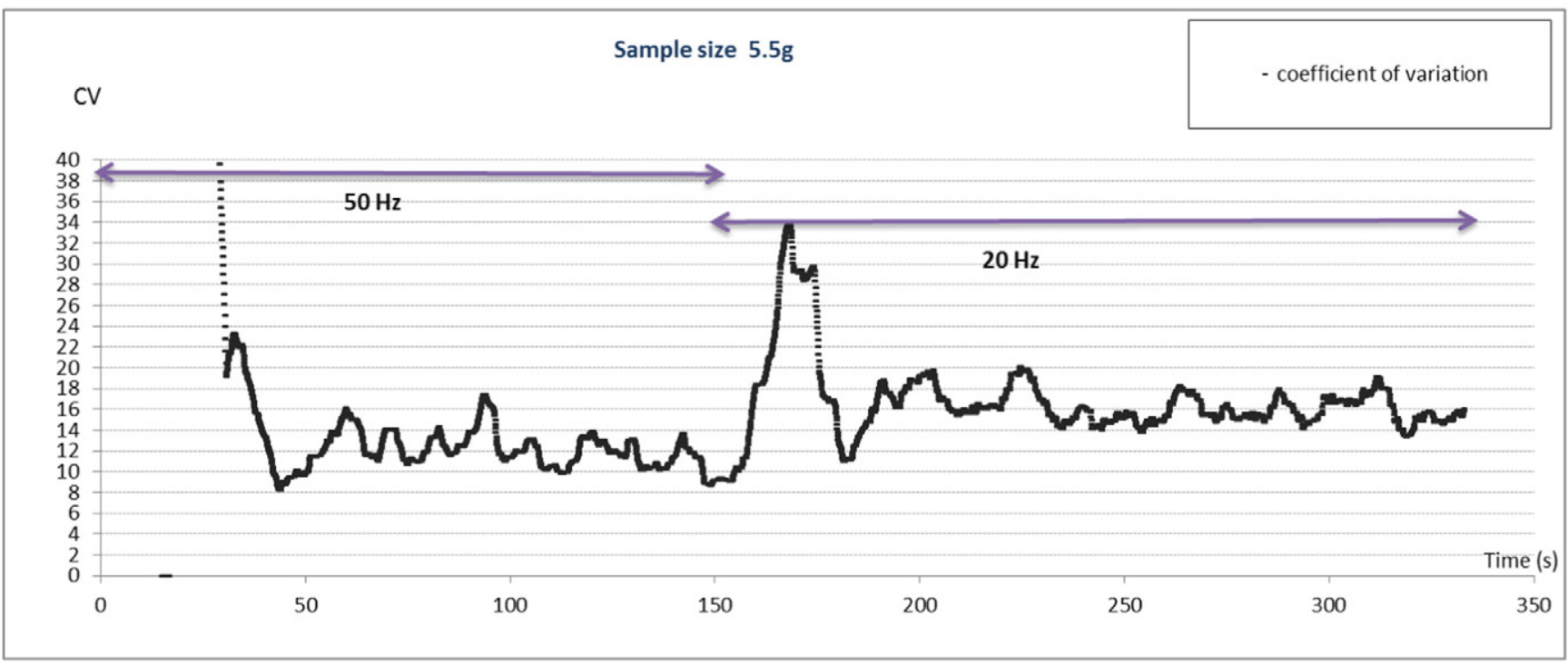

Fig. 12. Effect of a negative step ( $50 \mathrm{~Hz}-20 \mathrm{~Hz}$ ) of the impeller speed on fine fraction values (a) and mixture's CV (b). Results given for mixture B at a flowrate of $40 \mathrm{~kg} \cdot \mathrm{h}^{-1}$ and a scale of scrutiny corresponding to size 2 . 
that may in turn have an impact on mixture quality. In the following, we will focus on the effect of strong stepwise changes in impeller speed on both the fine fraction contents and the associated CV.

As remarked in the previous paragraph, the transitory period corresponding to the start of the mixer can be reduced by setting the stirrer's speed at its highest value, afterwards it may be fixed at the value that has been chosen for processing. However, this may not guarantee that the change in speed will be without impact on the mixture's quality. Fig. 11 reports on-line measurement of both fine fractions and CV during a start period for which the impeller speed has been set at $50 \mathrm{~Hz}$, and then abruptly changed to a value of $10 \mathrm{~Hz}$, for mixture $A$ and at a $40 \mathrm{~kg} \cdot \mathrm{h}^{-1}$ flowrate. As it can be appreciated, this negative step in impeller speed has a deep impact on the quality of the mixture, the peak measured on the $\mathrm{CV}$ rising to a value that is close to $30 \%$. The period of time corresponding to this transitory phases can be estimated to $70 \mathrm{~s}$, which is of the order of magnitude of the time needed to obtain a stable signal at $10 \mathrm{~Hz}$. This also means that the strategy of setting the speed of the stirrer to a bigger value during mixer's start is finally not worth the pain.
Another result may also be pointed out from the graph showing the evolution of fine fractions at the mixer's outlet: the abrupt decrease of fine fractions, from a $50 \%$ content to a $25 \%$ content, which also means that fine particles have been trapped in the mixer. This may be attributed to the expansion of the particle bed during the change from a high speed (small bed volume) to a small speed (higher bed volume), giving rise to segregation by percolation as commented previously.

A negative step has also been applied to the case of the lower-dosed mixture B, as it can be seen in Fig. 12. The impact of the change in impeller speed can also be measured by the time needed to record fine fractions of the same order than before the perturbation. Once again, fine particles are getting retained in the mixer because of size segregation, thanks to the increase in bed volume. Whatever the speed, and as expected from Fig. 10, the CV values are much higher than 6\%.

Fig. 13 reports results obtained during a positive step $(10 \mathrm{~Hz}$ to $30 \mathrm{~Hz}$ ) for mixture B under the same conditions as above. A clear change on the extent of the fluctuations is denoted, as the CV passes from a value which is close to $25 \%$ to a value of $12 \%$ approximatively. At the
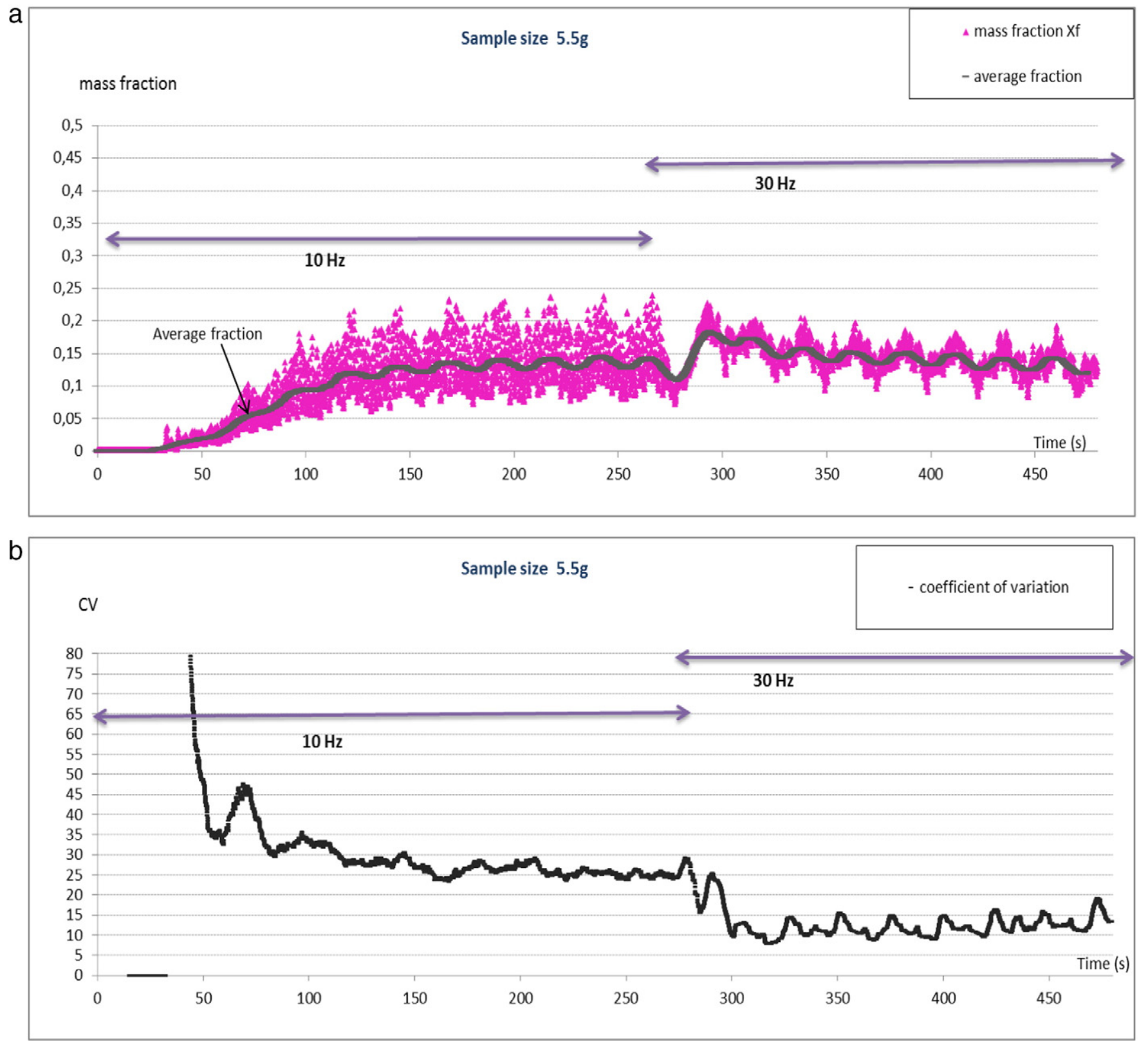

Fig. 13. Effect of a positive step ( $10 \mathrm{~Hz}-30 \mathrm{~Hz}$ ) of the impeller speed on fine fraction values (a) and mixture's CV (b). Results given for mixture $B$ at a flowrate of $40 \mathrm{~kg} \cdot \mathrm{h}^{-1}$ and a scale of scrutiny corresponding to size 2 . 
opposite of the negative steps, no perturbation at all is denoted during the transition from $10 \mathrm{~Hz}$ to $30 \mathrm{~Hz}$, the decrease of the CV happens practically stepwise. This is not exactly the case for outlet fine fractions that are experiencing an increase just after the step, to reach a smooth peak around $18 \%$, and then decrease slowly during some $100 \mathrm{~s}$ before reaching the steady-state nominal value of $12.5 \%$. It can be assumed that fine particles are getting released to the outlet by the segregated particle bed, which is richer in fine particles, during the decrease in bed volume. Finally, since mixture B is considered, it is not surprising to find CV values that would not be accepted in the context of a real production.

\section{Concluding remarks}

In this work, we have implemented an on-line image analysis set-up that is able to capture all the particles flowing out of a continuous mixer and therefore provide a real knowledge of the homogeneity of the mixture, without sampling errors. By doing so, we had access to an essential diagnosis of powder mixing inside the mixer, which is the presence of segregation by percolation that drove to an enrichment of the bed in fine particles. This may be kept in mind when dealing with industrial products of characteristics that are close to those of the model particles considered here. In fact, the attainment of a steady-state is not guaranteed, and things could get even worse at higher filling ratios of the mixer, or for smaller volume mixers that may not be able to absorb perturbations.

The increase of the rotational speed drives to small bed hold-ups that may lead to an emptying of the vessel. However, it also increases back-mixing and therefore helps the mixer to approach a perfectly mixed system as opposed to a plug flow situation which is favored by the horizontal mixer design. It would therefore be a clear improvement of the process if the outlet gate valve could be adjusted so as to ensure the same hold-up weight in the mixer, whatever the impeller speed.

The change in impeller speed during continuous operation through a negative step, is absolutely detrimental to the process. It should never be considered in case of potentially segregating systems. As a consequence, starting the mixer at a high speed, and then reducing it to a nominal value as it is sometimes done, is definitely a bad idea. This also points out that it may not always be possible to control the mixer by acting solely on the impeller speed, in particular for low-dosed mixtures. In this case, a different impeller type may be chosen, as well as another strategy for feeding, such as staged-feeding.

Modelling of powder flow and segregation inside the blender is the next step towards a better understanding of the dynamics of such systems. In future papers, we will report the results of a nonhomogeneous mesoscopic Markov chain model that has been derived and used to simulate transitory and steady-state operating of the GCM500. This will be an important consideration to account for when implementing a process control loop, which is the main object of our future research work.

\section{References}

[1] F. Roche, T. Page, J. Seville, Non-stop Pharma: Centuries in the Making, The Chemical Engineer, February 2013 28-31.

[2] D.M. Koller, A. Posch, G. Hörl, C. Voura, S. Radl, N. Urbanetz, Continuous quantitative monitoring of powder mixing dynamics by near-infrared spectroscopy, Powder Technol. 205 (2011) 87-96.

[3] L. Martínez, A. Peinado, L. Liesum, G. Betz, Use of near-infrared spectroscopy to quantify drug content on a continuous blending process: influence of mass flow and rotation speed variations, Eur. J. Pharm. Biopharm. (2013) 606-615.

[4] A.U. Vanarase, M. Jarvinen, J. Paaso, F.J. Muzzio, Development of a methodology to estimate error in the on-line measurements of blend uniformity in a continuous powder mixing process, Powder Technol. 241 (2013) 263-271.

[5] G.J. Vergote, T.R.M. De Beer, C. Vervaet, J.P. Remon, W.R.G. Baeyens, N. Diericx, Inline monitoring of a pharmaceutical blending process using FT-Raman spectroscopy, 21 (2004) 479-485.

[6] T.R.M. De Beer, C. Bodson, B. Dejaegher, B. Walczak, P. Vercruysse, A. Burggraeve, Raman spectroscopy as a process analytical technology (PAT) tool for the in-line monitoring and understanding of a powder blending process, J. Pharm. Biomed. Anal. 48 (2008) 772-779.

[7] Z. Wu, O. Tao, X. Dai, M. Du, X. Shi, Y. Qiao, Monitoring of a pharmaceutical blending process using near infrared chemical imaging, Vib. Spectrosc. 63 (2012) 371-379.

[8] S. Muerza, H. Berthiaux, S. Massol-Chaudeur, G. Thomas, A dynamic study of static mixing using on-line image analysis, Powder Technol. 128 (2002) 195-204.

[9] A. Realpe, C. Velasquez, Image processing and analysis for determination of concentrations of powder mixtures, Powder Technol. 134 (2003) 193-200.

[10] H. Berthiaux, K. Marikh, C. Gatumel, Continuous mixing of powder mixtures with pharmaceutical process constraints, Chem. Eng. Process. Process Intensif. 47 (2008) 2315-2322.

[11] T.A. Kingston, T.J. Heindel, Optical vizualization and composition analysis to quantify continuous granular mixing processes, Powder Technol. 262 (2014) 257-264.

[12] T.A. Kingston, T.J. Heindel, Granular mixing optimization and the influence of operating conditions in a double screw mixer, Powder Technol. 266 (2014) 144-155.

[13] P. Portillo, P.G. Ierapetritou, F.J. Muzzio, Characterization of continuous convective powder mixing processes, Powder Technol. 182 (2008) 368-378.

[14] A.U. Vanarase, F.J. Muzzio, Effect of operating conditions and design parameters in a continuous powder mixer, Powder Technol. 208 (2011) 26-36.

[15] J. Osorio, F.J. Muzzio, Effects of processing parameters and blade patterns on continuous pharmaceutical powder mixing, Chem. Eng. Process. Process Intensif. 109 (2016) 59-67

[16] M. Zhan, G. Sun, Y. Lu, X. Wang, Y. Zhang, Characterization of mixing of binary particles in a continuous colliding static mixer, Powder Technol. 291 (2016) 448-455.

[17] A.U. Vanarase, J.G. Osorio, F.J. Muzzio, Effects of powder flow properties and shear environment on the performance of continuous mixing of pharmaceutical powders, Powder Technol. 246 (2013) 63-72.

18] A. Sarkar, C.R. Wassgren, Simulation of a continuous granular mixer: effect of operating conditions on flow and mixing, Chem. Eng. Sci. 64 (2009) 2672-2682.

[19] V. Mizonov, H. Berthiaux, C. Gatumel, Theoretical study of optimal positioning of segregating components input into continuous mixer of solids, Part. Sci. Technol. Int. J. 33 (4) (2015) 339-341.

[20] S. Lakio, P. Tajarobi, H. Wikström, M. Fransson, J. Arnehed, T. Ervasti, S. Simonaho, J. Ketolainen, S. Folestad, S. Abrahmsen-Alami, Achieving a robust drug release from extended release tablet using an integrated continuous mixing and direct compression line, Int. J. Pharm. 511 (2016) 659-668.

[21] J.G. Khinast, J. Kruisz, M. Martinetz, S. Sacher, P.R. Wahl, I. Aigner, Development of a continuous production line for solid dosage forms via dry granulation, paper $n^{\circ}$ 400b, AIChE Annual Meeting, 2016 San Francisco (CA).

[22] C. Ammarcha, C. Gatumel, J.L. Dirion, M. Cabassud, V. Mizonov, H. Berthiaux, Predicting bulk powder flow dynamics in a continuous mixer operating in transitory regimes, Adv. Powder Technol. 23 (2012) 787-800.

[23] C. Ammarcha, C. Gatumel, J.L. Dirion, M. Cabassud, V. Mizonov, H. Berthiaux Transitory powder flow dynamics during emptying of a continuous mixer, Chem. Eng. Process. Process Intensif. 65 (2013) 68-75.

[24] H. Berthiaux, V. Mizonov, Applications of Markov chains in particulate process engineering - a review, Can. J. Chem. Eng. 82 (2004) 1143-1168.

[25] L. Devriendt, C. Gatumel, H. Berthiaux, Experimental evidence of mixture segregation by particle size distribution, Part. Sci. Technol. Int. J. 31 (6) (2013) 653-657.

[26] M. Aoun-Habbache, H. Berthiaux, M. Aoun, V. Mizonov, An experimental method and a Markov chain model to describe axial and radial mixing in a hoop mixer Powder Technol. 128 (2-3) (2002) 159-167.

[27] K. Marikh, H. Berthiaux, V. Mizonov, E. Barantzeva, D. Ponomarev, Flow analysis and Markov chain modelling to quantify the agitation effect in a continuous powder mixer, Chem. Eng. Res. Des. 84 (2006) 1059-1074

[28] H. Berthiaux, K. Marikh, V. Mizonov, D. Ponomarev, E. Barantzeva, Modeling continuous powder mixing by means of the theory of Markov chains, Part. Sci. Technol. 22 (2004) 379-389.

[29] K. Marikh, H. Berthiaux, V. Mizonov, E. Barantzeva, Experimental study of the stirring conditions taking place in a pilot plant continuous mixer of particulate solids, Powder Technol. 157 (2005) 138-143.

30] K. Marikh, H. Berthiaux, C. Gatumel, V. Mizonov, E. Barantzvea, Influence of stirre type on mixture homogeneity in continuous powder mixing: a model case and a pharmaceutical case, Chem. Eng. Res. Des. 86 (2008) 1027-1037.

[31] J.F. Demeyre, Characterizing Homogeneity of Powder Mixtures and Agitation in a Planetary Blender Triaxe ${ }^{\circledR}(\mathrm{PhD}$ dissertation) INP Toulouse, 2007.

[32] Characterization of powder mixtures (ch2) in, in: N. Harnby, Harnby, Edwards, Nienow (Eds.), Mixing in the Process Industry, Butterworth-Heinemann, Oxford 1997, pp. 25-41.

[33] R. Weinekötter R., Continuous mixing of fine particles, Part. Part. Syst. Charact. 12 (1) (1995) 46-53.

[34] S. Massol-Chaudeur, Characterizing Powder Mixture Quality for Low-Dosed Mixtures(PhD dissertation) INPL Nancy, 2000.

[35] N. Ehrhardt, M. Montagne, H. Berthiaux, C. Gatumel, B. Dalloz-Dubrujeaud Assessing the homogeneity of binary and ternary powder mixtures by on-line electrical capacitance, Chem. Eng. Process. 44 (2) (2005) 303-313.

[36] J.C. Williams, Cause and Effects of Segregation in Powders, Chemical Processing, Supplement, April 1965.

[37] A.D. Rosato, K.J. Stransburg, F. Prinz, R.H. Swendsen, Why the Brazil nuts are on top: size segregation of particulate matter by shaking, Phys. Rev. Lett. 58 (1987) 1038-1040.

[38] L. Vanel, A.D. Rosato, R.J. Dave, Size-dependent segregation in a 3D-vibrated bed, Powders Grains 385 (1997) 